\title{
Factors predicting short-term and long-term mortality in ICU patients with a malignancy: the importance of SOFA and ECOG performance status
}

Esther Nadine van der Zee ( $\nabla$ e.vanderzee@erasmusmc.nl )

Erasmus MC https://orcid.org/0000-0003-0431-4659

Lianne M. Noordhuis

Erasmus MC

Jelle L. Epker

Erasmus MC

Nikki van Leeuwen

Erasmus MC

Bas P.L. Wijnhoven

Erasmus MC

Dominique D. Benoit

Universitair Ziekenhuis Gent

Jan Bakker

Erasmus MC

Erwin J.O. Kompanje

Erasmus MC

Research article

Keywords: Mortality, Neoplasm, Critical Care, ICU, ECOG performance status, SOFA

Posted Date: August 19th, 2020

DOl: https://doi.org/10.21203/rs.3.rs-57362/v1

License: (a) This work is licensed under a Creative Commons Attribution 4.0 International License.

Read Full License 


\section{Abstract \\ Background}

Intensive Care Unit (ICU) triage decisions in patients with a malignancy can be difficult as clinicians have concerns about potential unfavourable outcomes. Therefore, clinicians may have doubts about the appropriateness of an ICU admission. The aim of this study was to assess the long-term mortality and performance status of critically ill patients with an active malignancy or a malignancy in their prior history admitted unplanned to the ICU. Furthermore, we aimed to compare the long-term mortality of those patients to the mortality of patients without a malignancy.

\section{Methods}

We conducted a retrospective cohort study in a large tertiary referral university hospital in the Netherlands. We categorized all adult patients with an unplanned admission to the ICU in 2017 in two groups: 1) the study population consisting of patients with an active malignancy and patients with a malignancy in their medical history (complete remission, CR) and 2) patients without a malignancy. Pearson's Chi-square tests and Independent Samples T-Tests or the Mann-Whitney U tests were used to evaluate the long-term mortality, the primary objective was 2-year mortality.

\section{Results}

Of the 1046 unplanned ICU admissions, 125 (12\%) patients had an active malignancy, $41(3.9 \%)<5$ year $\mathrm{CR}$ and $33(3.2 \%) \geq 5$ year CR. The 2-year mortality in the study population was significantly higher than in the population without a malignancy $(67.4 \%$ and $40.2 \%, \mathrm{P}<0.001)$. The median performance status at 2 years after ICU admission in the study population was 1 (IQR 0-2). SOFA score (OR 1.25; 95\% Cl 1.101.42) and ECOG performance status of 2 (OR 11.23; 95\% Cl 2.66-47.33), 3 (OR 5.91; 95\% Cl 1.77-19.79) and 4 (OR 13.16; 1.85-93.74) were independently associated with 2-year mortality.

\section{Conclusions}

Two thirds of the study population died within 2 years after ICU admission, which is higher than in the population without a malignancy. However, the majority of the study population had a good performance status at 2 years after ICU admission. The severity of the critical illness and the performance status before ICU admission are independently associated with 2-year mortality and should be considered as main factors in ICU triage.

\section{Background}


Over the past two decades, the number of patients with a malignancy requiring intensive care treatment has increased (1). Historically, during the 1980's and 1990's, patients with a malignancy were commonly considered ineligible for intensive care treatment due to their presumed unfavourable outcome $(2,3)$. However, a large European multicentre study shows that nowadays $15 \%$ of the patients admitted to the Intensive Care Unit (ICU) are patients with a malignancy (4).

Moreover, the ICU and hospital mortality of patients with an active malignancy has decreased significantly $(1,3,5)$. Patients with a solid malignancy show a similar mortality rate compared to critically ill patients admitted to the ICU without a malignancy (6). While literature regarding the mortality of critically ill patients with a hematological malignancy is heterogeneous (7-9), a decrease in mortality over the years has been described $(5,10)$.

Despite the encouraging trend of survival rates of patients with a malignancy admitted to the ICU, the decision to admit these patients to the ICU remains challenging, especially in the acute setting (11). In an area with rapid evolution of diagnostics and new innovative cancer treatments, reliable literature about short-term and long-term mortality and morbidity of patients with a malignancy admitted unplanned to the ICU is essential, in order to manage outcome expectations of health care providers, patients and families.

Effects of cancer treatment, such as cardiomyopathy or kidney failure, can become clinically evident even decades after completion of therapy (12-16). These effects of cancer treatment could influence the outcome of patients with a malignancy in their medical history admitted to the ICU. However, (long-term) mortality and performance status of patients with complete remission (CR) at the time of an unplanned ICU admission has not been extensively described in literature, except for patients who underwent a stem cell transplantation for a hematological malignancy.

The aim of this study was to assess the long-term mortality and performance status of critically ill patients with an active malignancy or a malignancy in their history admitted unplanned to the ICU. Furthermore, we aimed to compare the mortality in these patients to the mortality of patients admitted unplanned to the ICU without a malignancy. Last, we aimed to identify the factors associated with longterm mortality after ICU admission in patients with an active malignancy or a malignancy in their history.

\section{Methods}

We conducted a retrospective cohort study in a large tertiary referral university hospital ICU in the Netherlands. First, we identified all adult patients with an unplanned admission to the ICU in 2017 by using our hospital electronic database. Subsequently, we categorized the patients in two groups: 1) patients with an active malignancy and patients with a malignancy in their medical history (study population) and 2) patients without a malignancy. The study was approved by the ethical committee of our institute (MEC-2018-1172). 
We excluded patients with a diagnosis of a non-melanoma skin malignancy (squamous-cell skin cancer or basal-cell carcinoma) because of the relatively favourable prognosis of these tumours, usually without life threatening complications. Similarly, we also excluded patients with a premalignant condition, such as colon polyps.

Patient and ICU characteristics were collected. Patients with a malignancy in their medical history were defined as complete remission (CR), meaning no detectable malignancy based on the information available in the electronic database, medical reports and letters. The 5-year survival rate of patients with a malignancy is commonly used to describe the prognosis of a malignancy $(17,18)$, we therefore divided patients with $\mathrm{CR}$ in $\mathrm{CR}<5$ year and $\mathrm{CR}>5$ year. Since late deleterious effects of cancer therapies can occur even decades after completion of the cancer treatment (12-16), we did not exclude patients with a malignancy in their distant past. A metastatic solid malignancy was defined as an solid tumour with the presence of cancer cells present in distant organs or distant lymph nodes, determined by using the medical reports of haematologists and oncologists.

The comorbidity of the patients was measured by using the Charlson Comorbidity Index (CCI) (19). The Eastern Cooperative Oncology Group (ECOG) Performance Status was used to assess performance status in the month to fourteen days before the ICU admission (20). To evaluate the extent of the acute critical illness of the patients at ICU admission, the Sequential Organ Failure Assessment (SOFA) score was used $(21,22)$. The SOFA score is seen as an useful predictor of outcome $(23)$. Unplanned ICU admissions were defined as medical admissions and postoperative admission after emergency surgery. Readmissions were defined as a new ICU admission within 30 day after discharge from the ICU.

Comfort care was defined as the withdrawal of life-sustaining ICU treatment combined with the initiation of opioids or benzodiazepines when indicated. ICU and hospital mortality were defined as short-term mortality. Long-term mortality was defined as mortality at 6 months, 1 year or 2 years after ICU admission.

The primary objective was to assess 2-year mortality and performance status of critically ill patients with an active malignancy or a malignancy in their history admitted unplanned to the ICU (study population). Furthermore, to compare the mortality of those patients to a patients admitted unplanned to the ICU without a malignancy.

Secondary objectives were ICU and hospital mortality, mortality 6 months and 1 year after ICU admission and to identify factors associated with 2-year mortality after ICU admission in the study population.

\section{Statistical analysis}

Descriptive statistics were used to describe patient characteristics, ICU characteristics and mortality in the study population. Categorical variables are reported as numbers with percentage. Continuous variables are reported as mean and standard deviation for normally distributed data or, in case of a skewed distribution, median with 25th-75th interquartile range (IQR). 
Primary outcome

Mortality is reported as numbers with percentage. Performance status is reported as mean and standard deviation for normally distributed data or, in case of a skewed distribution, median with 25th-75th interquartile range. To compare the 2-year mortality and relevant patient and ICU characteristics (i.e. age, gender, SOFA score), we used Pearson's Chi-square tests or the Fisher's exact tests for categorical variables and Independent Samples T-Tests (normal distribution) or the Mann-Whitney U tests (skewed distributions) for continuous variables. A statistical test with a two tailed $p$ value $\leq 0.05$ was considered as significant.

\section{Secondary outcomes}

ICU and hospital mortality, mortality 6 months and 1 year after ICU admission were compared in a similar way as the primary outcome. For an illustrative purpose, a 2-year survival curve was made for the study population and the ICU population without a malignancy. The performance status was reported as median and IQR.

Univariate binary logistic regression was used to assess the association between 2-year mortality and the following variables in the study population: age, gender, ECOG PS before ICU admission, status of the malignancy (i.e. active, $\mathrm{CR}<5$ year, $\mathrm{CR}>5$ year), malignancy type (i.e. solid or haematological), admission reason, metastatic solid disease, stem cell transplantation, SOFA score at admission, sepsis and cancer treatment during ICU admission. Subsequently, variables with a p-value $<0.2$ in the univariate analysis were evaluated in a multivariate binary logistic regression analysis, except for variables with a small sample size or in case of collinearity.

Missing data were reported as unknown. Data were analysed by using IBMßSPSS ${ }^{\circledR}$ Statistics 24.0 (IBM, Chicago, IL, USA).

\section{Results}

In total, 2486 patients were admitted to the ICU, of which 1046 (42\%) unplanned admissions. Of these admissions, 221 patients (21.1\%) were diagnosed with a malignancy or had a malignancy in their medical history (study population). Patient characteristics are shown in Table 1. - Table 1 is longer than one A4 and is therefore placed at the end of this manuscript. This is the correct place for Table 1 - 
Table 1

Patient and ICU characteristics study population

\begin{tabular}{|ll|}
\hline Patient Characteristics & $\mathbf{( n = 2 2 1 )}$ \\
\hline Age & $66[59-73]$ \\
\hline Male & $142(64.3 \%)$ \\
\hline Comorbidity & $199(90 \%)$ \\
No. patients with comorbidity & $3[2-6]$ \\
CCl & $6[4-8]$ \\
Age-adjusted CCl & $2[1-3]$ \\
ECOG performance status & \\
\hline Type malignancy & $172(77.8 \%)$ \\
Solid malignancy & $37(16.8 \%)$ \\
Hematological malignancy & $10(4.5 \%)$ \\
Both solid and hematological malignancy & $2(0.9 \%)$ \\
Unknown type & \\
\hline Solid malignancy & $101(45.7 \%)$ \\
Active malignancy & $61(27.6 \%)$ \\
Complete Remission & $30(13.7 \%)$ \\
$<5$ year & $28(12.8 \%)$ \\
$>5$ year & \\
\hline Hematological malignancy & $21(9.5 \%)$ \\
Active malignancy & $13(5.9 \%)$ \\
Complete Remission 5 year & $10(4.5 \%)$ \\
\hline 5 year & $3(1.4 \%)$ \\
\hline Characteristics ICU admission & \\
\hline
\end{tabular}




\begin{tabular}{|ll|}
\hline Patient Characteristics & $\mathbf{( n = 2 2 1 )}$ \\
\hline Admission reason & $37(16.7 \%)$ \\
Emergency surgery & $180(81.5)$ \\
Medical & $4(1.8 \%)$ \\
Both & $56(25.3 \%)$ \\
Medical admission reasons & $35(15.9 \%)$ \\
Respiratory insufficiency & $26(11.7 \%)$ \\
Postoperative (emergency surgery) & $11(5.0 \%)$ \\
Sepsis & $19(8.6 \%)$ \\
Post cardiopulmonary resuscitation & $39(17.5 \%)$ \\
Neurological (non-traumatic) & $35(16.0 \%)$ \\
Other & \\
Combination & \\
\hline Readmissions & $58(26.2 \%)$ \\
\hline SOFA score at admission & $7[5-10]$ \\
\hline Mechanically ventilated & $140(63.3 \%)$ \\
\hline Vasopressors & $153(69.2 \%)$ \\
\hline Renal Replacement Therapy & $43(19.5 \%)$ \\
\hline Sepsis during ICU admission & $90(40.7 \%)$ \\
\hline Cancer treatment during ICU admission & $10(4.5 \%)$ \\
\hline Length of ICU stay (days) & 3 (1-0]) \\
\hline
\end{tabular}

The number of patients with an active malignancy was 125 (56.6\%). The majority of the patients were diagnosed with a solid malignancy $(172,77.8 \%)$. The different types of the malignancies are shown in supplementary material table 1 . The ICU admission reason was mostly medical (81.5\%), a quarter of these patients was admitted due to respiratory insufficiency (Table 1).

The 2-year mortality in our study population was $67.4 \%$ (Table 2). Two years after ICU admission, the median ECOG performance status in survivors was 1 (IQR $0-2$, Table 2), almost $75 \%$ of the survivors had an ECOG performance status of 0 or 1 . 
Table 2

Outcome study population

\begin{tabular}{|ll|}
\hline Mortality & $\mathbf{N}=221$ \\
\hline ICU & $67(30.3 \%)$ \\
\hline Hospital & $97(43.9 \%)$ \\
\hline 6 months & $128(57.9 \%)$ \\
\hline 1 -year & $142(64.3 \%)$ \\
\hline 2 -year & $149(67.4 \%)$ \\
\hline ECOG performance status & \\
\hline Post IC & $3[3-4]$ \\
\hline Post hospital & $2[2-3]$ \\
\hline 6 months post ICU & $1[1-2]$ \\
\hline 1 -year post ICU & $1[1-2]$ \\
\hline 2 -year post ICU & $1[0-2]$ \\
\hline ECOG performance status 2-years post ICU & \\
\hline 0 & $11(28.2 \%)$ \\
\hline 1 & $18(46.2 \%)$ \\
\hline 2 & $5(12.8 \%)$ \\
\hline 3 & $3(7.7 \%)$ \\
\hline 4 & $2(5.1 \%)$ \\
\hline
\end{tabular}

The 2-year mortality in our study population was significantly higher than the 2-year mortality in the population without malignancy $(40.2 \%, \mathrm{p}<0.001$, Table 3$)$. While gender and SOFA score in the study population were comparable to those of the population without a malignancy, the study population was significantly older (Table 3). 
Table 3

Characteristics and outcome of study population compared to population without malignancy

\begin{tabular}{|c|c|c|c|}
\hline & $\begin{array}{l}\text { Study population }(\mathrm{n}= \\
\text { 221) }\end{array}$ & $\begin{array}{l}\text { Without malignancy }(n= \\
825)\end{array}$ & P-value \\
\hline Age & $66[59-73]$ & 56 [44-67] & $<0.001 *$ \\
\hline Male & $142(64.3 \%)$ & $519(62.9 \%)$ & 0.75 \\
\hline $\begin{array}{l}\text { SOFA score at ICU } \\
\text { admission }\end{array}$ & $7[5-10]$ & $8[6-10]$ & 0.35 \\
\hline SOFA score at ICU death & $13[9-17]$ & 9 [8-13] & 0.07 \\
\hline ICU mortality & $67(30.3 \%)$ & $196(23.8 \%)$ & 0.06 \\
\hline Hospital mortality & $97(43.9 \%)$ & $244(29.6 \%)$ & $\begin{array}{l}< \\
0.001 *\end{array}$ \\
\hline 6 months mortality & $128(57.9 \%)$ & $288(34.9 \%)$ & $\hat{0} .001 *$ \\
\hline 1-year mortality & $142(64.3 \%)$ & $305(37 \%)$ & $\begin{array}{l}< \\
0.001 *\end{array}$ \\
\hline 2-year mortality & $149(67.4 \%)$ & $332(40.2 \%)$ & $\begin{array}{l}< \\
0.001 *\end{array}$ \\
\hline Start comfort care ICU & $77(34.8 \%)$ & $168(20.4)$ & $<.001 *$ \\
\hline Start comfort care ward & $12(5.4 \%)$ & $22(2.7 \%)$ & 0.16 \\
\hline
\end{tabular}

The ICU mortality in our study population was $30.3 \%$, which was not statistically significant different from the ICU mortality of the population without a malignancy $(23.8 \%, p \mathrm{0.06}$, Table 3$)$. In contrast, the hospital mortality, mortality 6 months and 1 year after ICU admission were significantly higher than in the population without a malignancy. During ICU stay, comfort care was significantly more frequently initiated in the study population than in the population without malignancy $(34.8 \%$ and $20.4 \%, p<0.001)$. Figure 1 shows a survival curve for illustrative purposes.

The binary univariate logistic regression analysis of the study population yielded a $p<0.2$ for the following variables: age, gender, ECOG PS before ICU admission, status of the malignancy (i.e. active, CR $<5$ year, CR $>5$ year), SOFA score at admission and sepsis during ICU admission (Table 4). 
Table 4

Univariate binary logistic regression analysis study population of possible predictors of 2-year mortality

\begin{tabular}{|llllll|}
\hline Variable & Patient cases & Mortality & OR & $95 \%$ Cl & P-value \\
\hline Age & - & - & 1.02 & $0.99-1.04$ & 0.15 \\
\hline Gender (male) & $142(64.3 \%)$ & $101(71.1 \%)$ & 1.59 & $0.89-2.84$ & 0.12 \\
\hline Comorbidity (CCI) & - & - & 1.11 & $0.98-1.25$ & 0.12 \\
\hline ECOG PS before ICU & $46(20.8 \%)$ & $22(47.8 \%)$ & - & - & - \\
\hline (ref) & $55(24.9 \%)$ & $39(70.9 \%)$ & 2.66 & $1.17-6.04$ & $0.02^{*}$ \\
1 & $38(17.2 \%)$ & $30(78.9 \%)$ & 4.09 & $1.55-10.80$ & $0.004^{*}$ \\
\hline 2 & $51(23.1 \%)$ & $37(72.5 \%)$ & 2.88 & $1.24-6.71$ & $0.01^{*}$ \\
3 & $15(6.8 \%)$ & $13(86.7 \%)$ & 7.09 & $1.44-35.02$ & $0.02^{*}$ \\
\hline 4 & & & & & \\
\hline Active malignancy (ref) & $125(56.6 \%)$ & $90(72 \%)$ & 0.75 & $0.35-1.60$ & 0.46 \\
CR<5 year & $41(18.6 \%)$ & $27(65.9 \%)$ & 0.53 & $0.24-1.17$ & 0.11 \\
CR 5 year & $33(14.9 \%)$ & $19(57.6 \%)$ & & & \\
\hline Solid malignancy (ref) & $172(77.8 \%)$ & $112(65.1 \%)$ & 1.45 & $0.66-3.19$ & 0.36 \\
\hline Hematological malignancy & $37(16.7 \%)$ & $27(73 \%)$ & 2.14 & $0.44-10.41$ & 0.35 \\
\hline Hematological and Solid & $10(4.5 \%)$ & $8(80 \%)$ & & & \\
\hline Emergency surgery (ref) & $37(16.7 \%)$ & $25(67.6 \%)$ & 0.98 & $0.46-2.10$ & 0.97 \\
\hline Medical reasons & $180(81.4 \%)$ & $121(67.2 \%)$ & & & 0.45 \\
\hline Metastatic malignancy & $60(27.1 \%)$ & $44(73.3 \%)$ & 1.38 & $0.61-3.11$ & 0.45 \\
\hline Stem cell transplantation & $12(5.4 \%)$ & $10(83.3 \%)$ & 2.52 & $0.54-11.81$ & 0.24 \\
\hline SOFA score & - & - & 1.26 & $1.13-1.40$ & $<0.001^{*}$ \\
\hline Sepsis & $90(40.7 \%)$ & $68(75.6 \%)$ & 1.91 & $1.06-3.46$ & $0.03^{*}$ \\
\hline Cancer treatment during ICU & $10(4.5 \%)$ & $6(60 \%)$ & 0.71 & $0.20-2.61$ & 0.61 \\
\hline
\end{tabular}

After adjustment for the confounders, an ECOG performance status before ICU admission of 2 (OR 11.23; $95 \% \mathrm{Cl} 2.66-47.33), 3$ (OR 5.91; $95 \% \mathrm{Cl} 1.77-19.79)$ and 4 (OR 13.16; 1.85-93.74) and SOFA score at admission (OR 1.25; 95\% Cl 1.10-1.42) were associated with 2-year mortality (Table 5). 
Table 5

Multivariate binary logistic regression analysis study population of possible predictors 2-year mortality

\begin{tabular}{|llll|}
\hline Covariate & OR & $95 \%$ Cl & P-value \\
\hline Age & 1.03 & $1.00-1.07$ & 0.06 \\
\hline Gender (male) & 0.68 & $0.31-1.49$ & 0.34 \\
CCI & 0.91 & $0.75-1.10$ & 0.32 \\
\hline ECOG PS 0 (ref) & 2.27 & $0.79-6.55$ & 0.13 \\
1 & 11.23 & $2.66-47.33$ & $0.001^{*}$ \\
2 & 5.91 & $1.77-19.79$ & $0.004^{*}$ \\
3 & 13.16 & $1.85-93.74$ & $0.01^{*}$ \\
4 & & & \\
\hline Active malignancy (ref) & 0.93 & $0.30-2.85$ & 0.90 \\
CR < 5 year & 0.42 & $0.14-1.28$ & 0.13 \\
CR $>5$ year & 0.50 & $0.12-2.04$ & 0.33 \\
Active+ CR & & & \\
\hline SOFA score & 1.25 & $1.10-1.42$ & $0.001^{*}$ \\
\hline Sepsis & 1.46 & $0.64-3.35$ & 0.37 \\
\hline
\end{tabular}

Likewise, ECOG performance status before ICU admission of 2 (OR 5.12; 95\% Cl 1.59-16.49), 3 (OR 5.81; $95 \% \mathrm{Cl} 2.36-19.64)$ and 4 (OR 6.66; 1.59-27.90) and SOFA score at admission (OR 1.19; 1.07-1.31) were independently associated with hospital mortality (supplementary material table 2 and 3 ).

Factors independently associated with 1-year mortality were age (OR 1.04; 95\% $\mathrm{Cl} 1.00-1.07$ ), ECOG performance status before ICU admission of 2 (OR 6.84; 95\% Cl 1.92-24.42) and $3(\mathrm{OR} 4.16 ; 95 \% \mathrm{Cl}$ 1.46-11.86) and SOFA score (OR 1.29; $95 \% \mathrm{Cl}(1.14-1.45)$ (supplementary material tables 4 and 5).

No differences in mortality and ECOG performance status after ICU admission between patients with an active malignancy and patients with complete remission were seen (supplementary material table 6). Despite the higher SOFA score in patients with a hematological malignancy, no differences in mortality and ECOG performance status were seen between patients with a solid malignancy and patients with a hematological malignancy, supplementary material table 7.

Both short-term and long-term mortality was significantly higher in patients with an active malignancy than in patients without a malignancy (supplementary material table 8 ). While long-term mortality was 
significantly higher in patients with CR than in patients without a malignancy, no statistical difference in short-term mortality was seen (supplementary material table 9).

\section{Discussion}

Clinicians may have doubts about the appropriateness of an ICU admission in patients with a malignancy or a malignancy in their medical history. Reliable literature about long-term mortality and morbidity of patients with a malignancy admitted unplanned to the ICU is essential in order to manage outcome expectations of health care providers, patients and families. We found in our study that a poor functional status as measured by the ECOG performance status, SOFA score at admission and, to a lesser extent, age were independently associated with a poorer short-term and long-term outcome.

Two thirds of the patients with an active malignancy or a malignancy in their medical history die within 2 years after ICU admission. The 2-year mortality of the study population is approximately 1.5 times higher than the 2-year mortality in the population without malignancy. One explanation for this difference could be the weakened condition with a poor ECOG performance status directly after ICU discharge in the study population. The performance status was still reduced at hospital discharge, influencing long-term mortality.

The hospital mortality of our study population was similar to other European literature $(44 \%)(3-5,24-$ 27). In contrast, the long-term mortality in our study was higher than in other studies (28-34). An explanation may be the difference in case-mix. We included only unplanned ICU admissions, while most other studies included patients with planned ICU admissions as well. Moreover, our study population had a higher SOFA score and received more often organ support.

We found that comfort care was started more often in our study population (35\%) than in our population without cancer (20\%) and the study population of a specialised Portuguese Cancer institute (13\%) (27). Besides differences in case-mix, end-of-life (EoL) decisions could be influenced by many factors, such as religious beliefs, cultural backgrounds, and the ethical climate of the team (35). Consequently, the presence of malignancy or a malignancy in the medical history could influence EoL decisions by clinicians. By starting comfort care, we might spare patients from invasive treatments, such as the insertion of multiple intravenous catheters or prolonged mechanical ventilation, who would have died regardless of ICU treatment. Another explanation exists. Literature shows that prognostication for an individual patient remains difficult (32) and suggests the existence of self-fulfilling prophecy (SFP) in medical decision making, especially in EoL decisions (36). As comfort care inevitable leads to death, we might deprive patients with a malignancy the possibility of prolonged survival if we misjudge the prognosis of an individual patient. To prevent such a misjudgement, EoL decisions should be made in a multidisciplinary meeting.

Within the study population, no statistically significant difference in short-term mortality and long-term mortality was seen between patients with an active malignancy and patients with complete remission. However, a clinically relevant difference in 1 -year mortality $(67.2 \%$ vs $58.2 \%)$ and 2 -year mortality (72\% vs 
59.5\%) was seen between these groups. This finding suggests that for short-term mortality, other factors such as comorbidity and severity of illness should be considered as important factor for outcome, while the status of the malignancy plays an increasingly important role in long-term mortality. Patients with complete remission showed higher long-term mortality rates when compared to the patients without a malignancy. This finding may suggest an influence of previous cancer treatment (and therefore having a malignancy in $\mathrm{CR}$ ) on long-term mortality. To our knowledge, the mortality of patients with an active malignancy compared to $\mathrm{CR}$ and the general population has not been directly described in the current literature.

Despite the higher mortality, we think it is important to note that the majority of the survivors had a good performance status 2 years after ICU admission, both in patients with an active malignancy as in patients with complete remission. Seventy-five percent of the patients with a known ECOG performance status scored 0 or 1 . Our findings are consistent with Zafra and co-workers, in their study $79 \%$ of the survivors at 1 year after ICU admission showed an ECOG performance status of 0-2 (37).

The finding that performance status (measured by the ECOG performance status) was independently associated with short-term mortality and long-term mortality $(33,34,38-40)$ is in line with other literature. Similar to our study, severity of illness (measured by the SOFA score) has been described in literature as predictor for short-term mortality in patients with a malignancy $(30,31,41)$ and long-term mortality $(38$, $39,42)$. Studies which describe SOFA score and performance status as long-term predictor have maximal 1 year of follow up after ICU admission. Our study shows that SOFA score and performance status are independently associated with 2 year mortality as well. To a lesser degree, age was a factor associated with mortality in our study. After an ICU admission, aging is associated with an increased risk of mortality in the 3 years after hospital discharge (43).

As SOFA score and ECOG performance status before ICU admission were independent predictors for short-term mortality and long-term mortality, the decision to deny a patient with a malignancy or a malignancy in their medical history an ICU admission should not solely be based on the presence of a malignancy. Instead, physicians should take the severity of illness and performance status into account before referring or admitting a patient to the ICU. In addition, ICU admission should also depend on the prognostic expectations of the patient. However, prognostication at individual patient level by clinicians remains difficult $(1,32)$. It is especially difficult in patients with a malignancy, due to the many factors related to the underlying malignancy (e.g. stage, type, hormone receptor status), and the estimation whether the patient will be able to receive future anti-cancer treatment after ICU admission $(1,32)$. Moreover, poor communication regarding outcome and expectations towards other health care providers or the patient and family has been described, either due to insufficient knowledge concerning prognostication or communication, or due to difficulty with sharing a poor prognosis $(32,44,45)$. To improve prognostication and communication, good collaboration with open communication in multidisciplinary meetings and joint education regarding expectations and outcomes is essential (32).

\section{Limitations and strengths}


First, the most important limitation is the heterogeneity of the study population. However, by using a binary logistic regression analysis, the heterogeneity of the type of tumour (solid vs hematological) and the status of the malignancy (active vs CR) was minimalized. Literature shows clearly late negative effects of cancer therapies, even decades after completion of the cancer treatment (12-16). We therefore did not exclude patients with a malignancy in their distant past, which caused a wide variation of duration of $\mathrm{CR}$.

Second, selection bias might have influenced our outcome, as our ICU physicians already made an admission decision before ICU admission. Nevertheless, our study population accounted for $20 \%$ of the unplanned ICU admissions, which is comparable to other literature. Therefore, the influence of selection bias should be limited.

Third, performance status is not similar to quality of life. However, since literature regarding long-term performance status after ICU admission in patients with a malignancy is very limited, our message of a good long-term performance status is important.

Fourth, data were collected from a single institution, which can restrict generalizability. However our institute is the biggest university clinic in the Netherlands, covering oncologic patient care for a population up to 3 million people.

Last, this was a retrospective study, and all the limitations of a retrospective review could be inherent in our study.

\section{Conclusion}

This study shows that two thirds of the patients with an active malignancy or a malignancy in their medical history died within 2 years after ICU admission. Two year mortality in the study population is approximately 1.5 times higher than the 2-year mortality in the population without malignancy. However, the majority of the survivors in the study population had a good performance status 2 years after ICU admission. The severity of the critical illness and the performance status before ICU admission are independently associated with 2-year mortality. Severity of illness, performance status and prognosis should be the main factors in ICU admission decisions.

\section{Abbreviations}

Intensive Care Unit (ICU)

Complete remission (CR)

Interquartile range (IQR)

Sequential Organ Failure Assessment Score (SOFA score) 
Eastern Cooperative Oncology Group Performance Status (ECOG performance status or ECOG PS)

Charlson Comorbidity Index (CCl)

Odds ratio (OR)

Confidence interval $(\mathrm{Cl})$

End-of-Life (EoL)

Self-fulfilling prophecy (SFP)

\section{Declarations}

\section{Ethics approval and consent to participate}

The study was approved by the ethical committee of our institute (Erasmus Medical Center): The Erasmus MC Medical Ethics Review Committee (reference number MEC-2018-1172).

\section{Consent for publication}

Not applicable

\section{Availability of data and materials}

The datasets used and/or analysed during the current study are available from the corresponding author on reasonable request.

\section{Competing interests}

The authors declare that they have no competing interests

\section{Funding}

Not applicable

\section{Authors' contributions}

EZ: conceptualization, design, acquisition, analysis and interpretation of data, writing-original draft and writing- review and editing. LN: data acquisition, analysis and interpretation of data, writing original draft, JE: conceptualization, design, interpretation of data, writing- review and editing, NL: analysis and interpretation of data, writing- review and editing, BW: interpretation of data, writing- review and editing, DB: design, analysis and interpretation of data, writing- review and editing, JB: design, analysis and 
interpretation of data, writing- review and editing, EK: conceptualization, design, interpretation of data, writing- review and editing. All authors approved the final manuscript.

\section{Acknowledgements}

Not applicable

\section{References}

1. Azoulay E, Schellongowski P, Darmon M, Bauer PR, Benoit D, Depuydt P, et al. The Intensive Care Medicine research agenda on critically ill oncology and hematology patients. Intensive Care Med. 2017;43(9):1366-82.

2. Guidelines for intensive care unit. admission, discharge, and triage. Task Force of the American College of Critical Care Medicine, Society of Critical Care Medicine. Crit Care Med. 1999;27(3):633-8.

3. Ostermann M, Ferrando-Vivas P, Gore C, Power S, Harrison D. Characteristics and Outcome of Cancer Patients Admitted to the ICU in England, Wales, and Northern Ireland and National Trends Between 1997 and 2013. Crit Care Med. 2017;45(10):1668-76.

4. Taccone FS, Artigas AA, Sprung CL, Moreno R, Sakr Y, Vincent JL. Characteristics and outcomes of cancer patients in European ICUs. Crit Care. 2009;13(1):R15.

5. Darmon M, Bourmaud A, Georges Q, Soares M, Jeon K, Oeyen S, et al. Changes in critically ill cancer patients' short-term outcome over the last decades: results of systematic review with meta-analysis on individual data. Intensive Care Med. 2019;45(7):977-87.

6. Puxty K, McLoone P, Quasim T, Sloan B, Kinsella J, Morrison DS. Risk of Critical Illness Among Patients With Solid Cancers: A Population-Based Observational Study. JAMA Oncol. 2015;1(8):1078-85.

7. Corcia Palomo Y, Knight Asorey T, Espigado I, Martin Villen L, Garnacho Montero J Mortality of Oncohematological Patients Undergoing Hematopoietic Stem Cell Transplantation Admitted to the Intensive Care Unit. Transplant Proc. 2015;47(9):2665-6.

8. Mokart D, Granata A, Crocchiolo R, Sannini A, Chow-Chine L, Brun JP, et al. Allogeneic hematopoietic stem cell transplantation after reduced intensity conditioning regimen: Outcomes of patients admitted to intensive care unit. J Crit Care. 2015;30(5):1107-13.

9. Pene F, Aubron C, Azoulay E, Blot F, Thiery G, Raynard B, et al. Outcome of critically ill allogeneic hematopoietic stem-cell transplantation recipients: a reappraisal of indications for organ failure supports. J Clin Oncol. 2006;24(4):643-9.

10. de Vries VA, Muller MCA, Sesmu Arbous M, Biemond BJ, Blijlevens NMA, Kusadasi N, et al. Time trend analysis of long term outcome of patients with haematological malignancies admitted at dutch intensive care units. $\mathrm{Br} \mathrm{J}$ Haematol. 2018;181(1):68-76. 
11. Thiery G, Azoulay E, Darmon M, Ciroldi M, De Miranda S, Levy V, et al. Outcome of cancer patients considered for intensive care unit admission: a hospital-wide prospective study. J Clin Oncol. 2005;23(19):4406-13.

12. Curigliano G, Cardinale D, Dent S, Criscitiello C, Aseyev O, Lenihan D, et al. Cardiotoxicity of anticancer treatments: Epidemiology, detection, and management. CA Cancer J Clin. 2016;66(4):309-25.

13. Ferrari S, Pieretti F, Verri E, Tolentinis L, Cesari M, Versari M, et al. Prospective evaluation of renal function in pediatric and adult patients treated with high-dose ifosfamide, cisplatin and high-dose methotrexate. Anticancer Drugs. 2005;16(7):733-8.

14. Kasuya G, Ogawa K, Iraha S, Nagai Y, Shiraishi M, Hirakawa M, et al. Severe late complications in patients with uterine cancer treated with postoperative radiotherapy. Anticancer Res. 2011;31(10):3527-33.

15. Numico G, Longo V, Courthod G, Silvestris N. Cancer survivorship: long-term side-effects of anticancer treatments of gastrointestinal cancer. Curr Opin Oncol. 2015;27(4):351-7.

16. Stenehjem JS, Smeland KB, Murbraech K, Holte H, Kvaloy S, Thorsen L, et al. Cardiorespiratory fitness in long-term lymphoma survivors after high-dose chemotherapy with autologous stem cell transplantation. Br J Cancer. 2016;115(2):178-87.

17. Maruvka YE, Tang M, Michor F. On the validity of using increases in 5-year survival rates to measure success in the fight against cancer. PLoS One. 2014;9(7):e83100.

18. Allemani C, Matsuda T, Di Carlo V, Harewood R, Matz M, Niksic M, et al. Global surveillance of trends in cancer survival 2000-14 (CONCORD-3): analysis of individual records for 37513025 patients diagnosed with one of 18 cancers from 322 population-based registries in 71 countries. Lancet. 2018;391(10125):1023-75.

19. de Groot V, Beckerman H, Lankhorst GJ, Bouter LM. How to measure comorbidity. a critical review of available methods. J Clin Epidemiol. 2003;56(3):221-9.

20. ECOG performance status. Eastern Cooperative Oncology Group; accessed 02 August 2020 [updated 2020. Available from: https://ecog-acrin.org/resources/ecog-performance-status.

21. Baradari AG, Firouzian A, Davanlou A, Aarabi M, Daneshiyan M, Kiakolaye YT. Comparison of Patients' Admission, Mean and Highest Sofa Scores in Prediction of Icu Mortality: A Prospective Observational Study. Mater Sociomed. 2016;28(5):343-7.

22. Falcao ALE, Barros AGA, Bezerra AAM, Ferreira NL, Logato CM, Silva FP, et al. The prognostic accuracy evaluation of SAPS 3, SOFA and APACHE II scores for mortality prediction in the surgical ICU: an external validation study and decision-making analysis. Ann Intensive Care. 2019;9(1):18.

23. Ferreira FL, Bota DP, Bross A, Melot C, Vincent JL. Serial evaluation of the SOFA score to predict outcome in critically ill patients. JAMA. 2001;286(14):1754-8.

24. Hampshire PA, Welch CA, McCrossan LA, Francis K, Harrison DA. Admission factors associated with hospital mortality in patients with haematological malignancy admitted to UK adult, general critical 
care units: a secondary analysis of the ICNARC Case Mix Programme Database. Crit Care. 2009;13(4):R137.

25. Mokart D, Etienne A, Esterni B, Brun JP, Chow-Chine L, Sannini A, et al. Critically ill cancer patients in the intensive care unit: short-term outcome and 1-year mortality. Acta Anaesthesiol Scand. 2012;56(2):178-89.

26. Murphy K, Cooksley T, Haji-Michael P. Short- and long-term outcomes of patients with solid tumours following non-surgical intensive care admission. Qjm. 2018;111(6):379-83.

27. Tavares M, Neves I, Chacim S, Coelho F, Afonso O, Martins A, et al. Withdrawing and Withholding Life Support in Patients With Cancer in an ICU Setting: A 5-Year Experience at a European Cancer Center. J Intensive Care Med. 2018;33(7):415-9.

28. Gruber PC, Achilleos A, Speed D, Wigmore TJ. Long-stay patients with cancer on the intensive care unit: characteristics, risk factors, and clinical outcomes. Br J Anaesth. 2013;111(6):1026-7.

29. Puxty K, McLoone P, Quasim T, Sloan B, Kinsella J, Morrison DS. Characteristics and Outcomes of Surgical Patients With Solid Cancers Admitted to the Intensive Care Unit. JAMA Surg. 2018;153(9):834-40.

30. Sauer CM, Dong J, Celi LA, Ramazzotti D. Improved Survival of Cancer Patients Admitted to the Intensive Care Unit between 2002 and 2011 at a U.S. Teaching Hospital. Cancer Res Treat. 2019;51(3):973-81.

31. Azoulay E, Mokart D, Pene F, Lambert J, Kouatchet A, Mayaux J, et al. Outcomes of critically ill patients with hematologic malignancies: prospective multicenter data from France and Belgium-a groupe de recherche respiratoire en reanimation onco-hematologique study. J Clin Oncol. 2013;31(22):2810-8.

32. Oeyen SG, Benoit DD, Annemans L, Depuydt PO, Van Belle SJ, Troisi RI, et al. Long-term outcomes and quality of life in critically ill patients with hematological or solid malignancies: a single center study. Intensive Care Med. 2013;39(5):889-98.

33. Borcoman E, Dupont A, Mariotte E, Doucet L, Joseph A, Chermak A, et al. One-year survival in patients with solid tumours discharged alive from the intensive care unit after unplanned admission: A retrospective study. J Crit Care. 2020;57:36-41.

34. Normilio-Silva K, de Figueiredo AC, Pedroso-de-Lima AC, Tunes-da-Silva G, Nunes da Silva A, Delgado Dias Levites A, et al. Long-Term Survival, Quality of Life, and Quality-Adjusted Survival in Critically III Patients With Cancer. Crit Care Med. 2016;44(7):1327-37.

35. Benoit DD, Jensen HI, Malmgren J, Metaxa V, Reyners AK, Darmon M, et al. Outcome in patients perceived as receiving excessive care across different ethical climates: a prospective study in 68 intensive care units in Europe and the USA. Intensive Care Med. 2018;44(7):1039-49.

36. Wilkinson D. The self-fulfilling prophecy in intensive care. Theor Med Bioeth. 2009;30(6):401-10.

37. Marta Z, Andres C, Maria Angeles V, Manuel Sánchez C, Alejandra Ivars R, Inmaculada Ballester N, et al. Long-term survival and performance status of cancer patients after discharge from ICU (intensive care unit). J Clin Oncol. 2018;36(15_suppl):e18744-e. 
38. Camou F, Didier M, Leguay T, Milpied N, Daste A, Ravaud A, et al. Long-term prognosis of septic shock in cancer patients. Support Care Cancer. 2020;28(3):1325-33.

39. Lee DS, Suh GY, Ryu JA, Chung CR, Yang JH, Park CM, et al. Effect of Early Intervention on Long-Term Outcomes of Critically III Cancer Patients Admitted to ICUs. Crit Care Med. 2015;43(7):1439-48.

40. Lopez R, Samtani SR, Montes JM, Perez R, Martin MJ, Salazar A, et al. Survival of Critically III Oncologic Patients Requiring Invasive Ventilatory Support: A Prospective Comparative Cohort Study With Nononcologic Patients. J Glob Oncol. 2019;5:1-8.

41. Xia R, Wang D. Intensive care unit prognostic factors in critically ill patients with advanced solid tumors: a 3-year retrospective study. BMC Cancer. 2016;16:188.

42. Fisher R, Dangoisse C, Crichton S, Whiteley C, Camporota L, Beale R, et al. Short-term and mediumterm survival of critically ill patients with solid tumours admitted to the intensive care unit: a retrospective analysis. BMJ Open. 2016;6(10):e011363.

43. Atramont A, Lindecker-Cournil V, Rudant J, Tajahmady A, Drewniak N, Fouard A, et al. Association of Age With Short-term and Long-term Mortality Among Patients Discharged From Intensive Care Units in France. JAMA Network Open. 2019;2(5):e193215-e.

44. Back AL, Anderson WG, Bunch L, Marr LA, Wallace JA, Yang HB, et al. Communication about cancer near the end of life. Cancer. 2008;113(7 Suppl):1897-910.

45. Lamont EB, Christakis NA. Prognostic disclosure to patients with cancer near the end of life. Ann Intern Med. 2001;134(12):1096-105.

\section{Figures}




\section{Survival curve 1a}

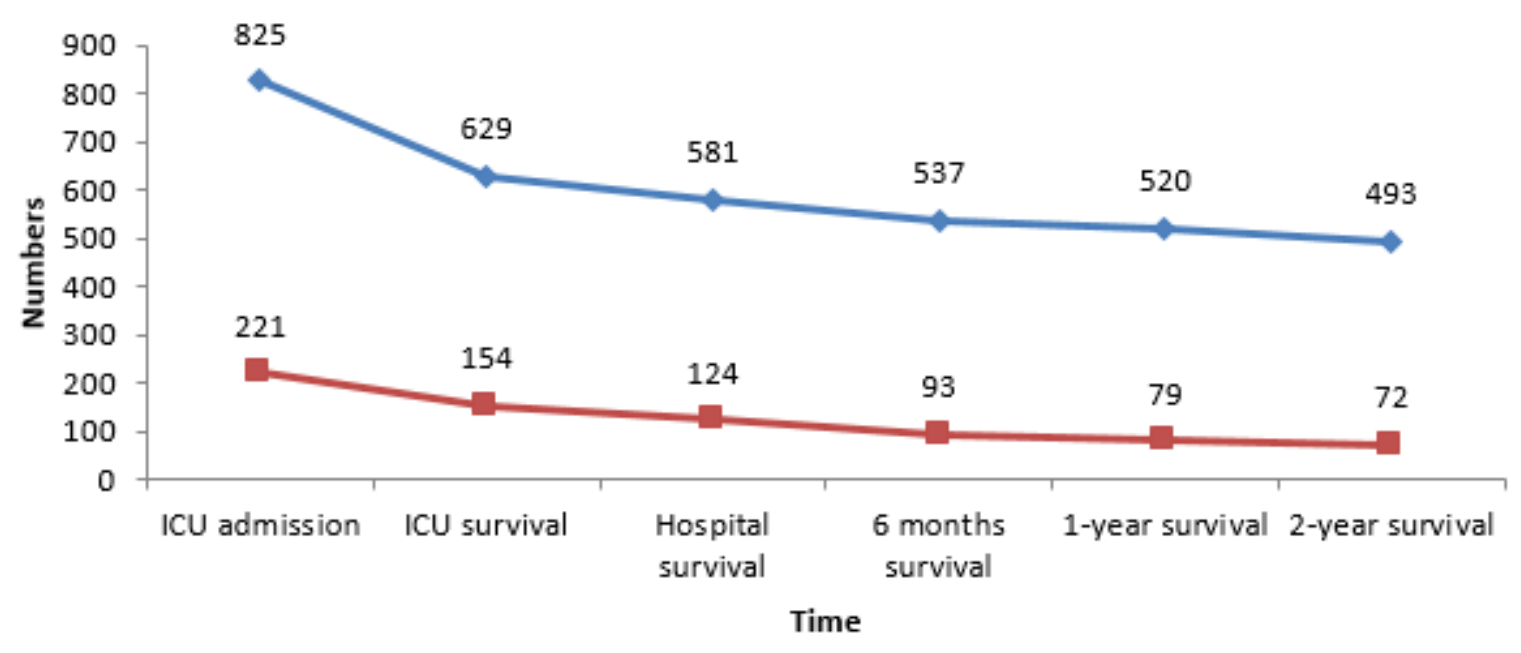

$\longrightarrow$ Population without malignancy $\rightarrow$ Study population

(Patients with a malignancy or complete remission)

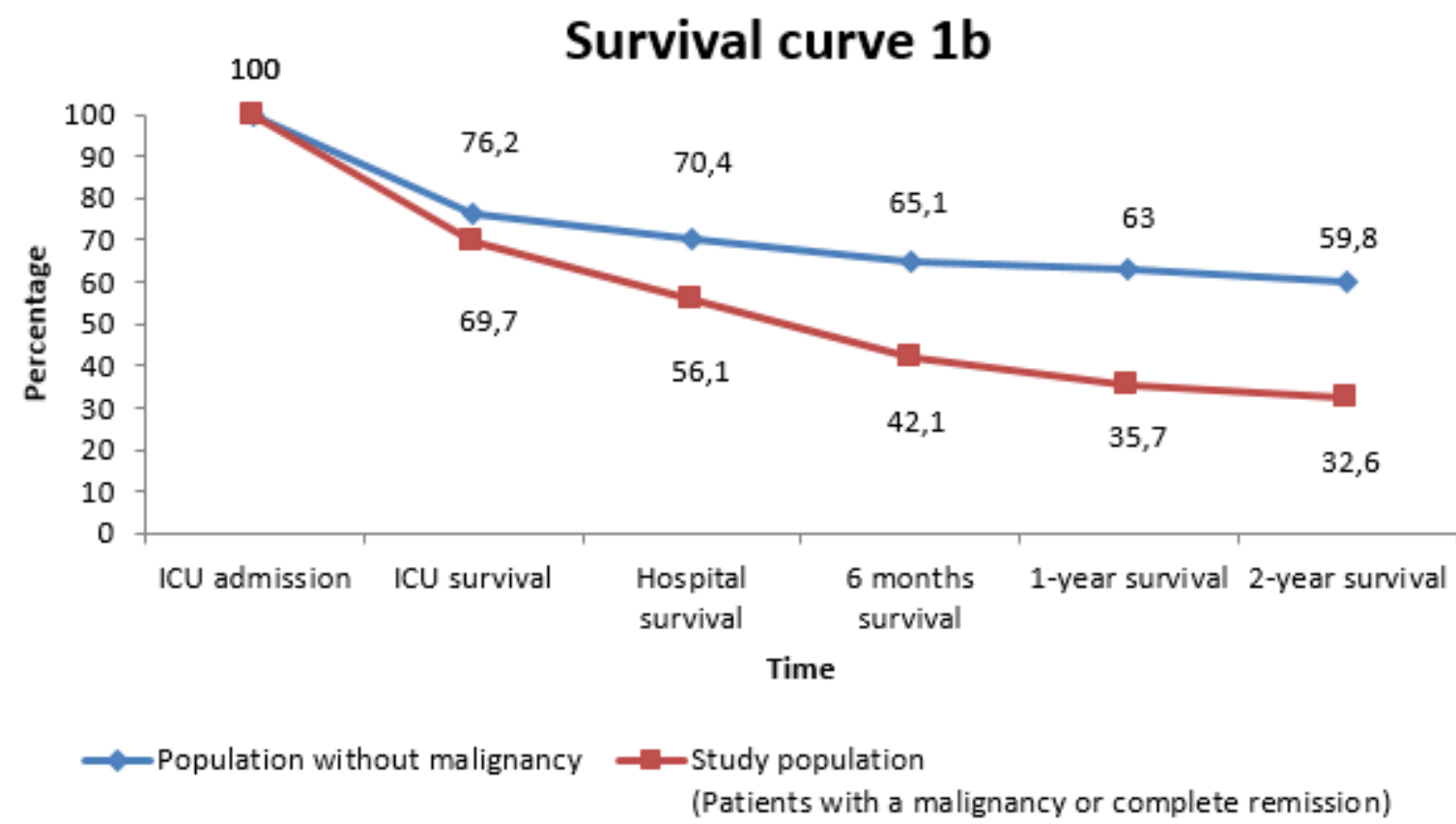

\section{Figure 1}

1a: Survival curve 1a. 1b: Survival curve 1b. Survival curve of study population and population without a malignancy in numbers (a) and percentages (b) Legend: Blue line: population without malignancy Red line: study population (patients with a malignancy or complete remission)

\section{Supplementary Files}

This is a list of supplementary files associated with this preprint. Click to download.

- Supplementarytable9.docx 
- Supplementarytable8.docx

- Supplementarytable7.docx

- Supplementarytable6.docx

- Supplementarytable5.docx

- Supplementarytable4.docx

- Supplementarytable3.docx

- Supplementarytable2.docx

- Supplementarytable1.docx 